\title{
Georg Simmel (1858-1918)
}

\author{
Otthein Rammstedt; \\ Natàlia Cantó i Milà \\ Universitat de Bielefeld (Alemanya)
}

Traducció de l'anglès per Natàlia Cantó i Milà. Bielefeld, octubre de 2000

\section{Resum}

Aquest article presenta una visió general de la vida i el pensament de Georg Simmel des de la perspectiva de les Ciències Socials. Després d'una breu introducció biogràfica, una discussió dels aspectes de la seva obra propera a les CCSS, particularment a la biologia, és el principal focus del text. Al costat de Max Weber i Emile Durkheim, Simmel és un dels grans clàssics teòrics de la Sociologia, i tal com es mostra a continuació contribueix substancialment al desenvolupament de la disciplina, alliberada des de la necessitat d'abastar l'estudi de la societat com un tot. D'aquesta manera, s'exposarà una visió dels conceptes teòrics fonamentals de Simmel, amb la intenció de mostrar la seva relevança central en el camp de les CCSS.

Paraules clau: Simmel, sociologia, «forma», tu i jo.

\begin{abstract}
This article presents a general overview of the life and thought of Georg Simmel from the perspective of the social sciences. After a brief biographical introduction, a discussion of those aspects of his oeuvre which enjoy close proximity with the social sciences, particularly sociology, constitutes the main focus of the text. Together with Max Weber and Emile Durkheim, Simmel is one of the great classic theorists of sociology, and, as shown below, contributes substantially to the development of the discipline, freeing it from needing to be an all-encompassing study of society as a whole. Thus, an overview of Simmel's fundamental theoretical concepts will be delivered, with the aim of illustrating his central relevance to the field of the social sciences.
\end{abstract}

Key words: Simmel, sociology, "form», you and me.

\section{Sumari}

Georg Simmel. Un breu retrat Tu i jo

Georg Simmel i les ciències socials

L'objecte de la sociologia

El concepte de «forma»
Una proposta per a tres sociologies

Simmel i la sociologia moderna

Bibliografia 


\section{Georg Simmel. Un breu retrat}

Georg Simmel va néixer al cor de Berlín, l'1 de març de 1858. Era el fill petit de Flora i Eduard Simmel, tots dos d'origen jueu però convertits al cristianisme (ell al catolicisme, ella al protestantisme). Després de la prematura mort d'Eduard l'any 1874, la família Simmel va patir serioses dificultats econòmiques. El jove Georg, però, no en va haver de notar les conseqüències, gràcies a la intervenció i ajuda de Julius Friedländer, un amic de la família i cofundador de la coneguda editorial de música Peters. Friedländer sentia una forta simpatia pel petit dels Simmel i de seguida el va prendre com el seu protegit. Així, aquest va poder cursar estudis superiors (Gymnasium) i seguidament estudiar filosofia, història, història de l'art i psicologia social ( $V \ddot{o l}$ kerpsychologie) a la Universitat de Berlín. Tot i que, després de força problemes, va rebre el títol de doctor en filosofia l'any 1881. El seu primer esbós de tesi, «Estudis psicològics i etnològics sobre els orígens de la música», no va ésser acceptat, i, en el seu lloc, va haver de presentar un treball que havia escrit prèviament sobre Kant, "Sobre l'essència de la matèria: L'ésser de la matèria segons la monadologia física de Kant», amb el qual havia guanyat un premi atorgat pel kàiser ${ }^{1}$. L'habilitació ${ }^{2}$ va arribar l'any 1885 . Aquesta també va aixecar polseguera a la facultat de filosofia i no el va deixar en gaire bona posició davant certs professors de la casa ${ }^{3}$. La seva carrera acadèmica començà immediatament després com a Privatdozent ${ }^{4}$. No va ser fins l'any 1901 que va obtenir una càtedra extraordinària sense dret a salari i encara va haver d'esperar fins l'any 1914 per, finalment, ser cridat per ocupar una càtedra ordinària a la facultat de filosofia, no de Berlín, sinó a la Universitat d'Estrasburg, on hi va romandre fins a la seva mort, el 26 de setembre de 1918, poc abans del final de la Primera Guerra Mundial.

Ja en vida de Simmel, aquest fou una persona coneguda al món cultural de Berlín. No es va restringir a afers científics o acadèmics, ans contínuament mostrà un gran interès per la política del seu temps, pels problemes socials del moment i pel món de les arts. Va cercar la presència, el contacte i el diàleg d'intel.lectuals i artistes de l'època. Es va casar amb la pintora Gertrud Kinel, amb la qual va tenir un fill, Hans, i va mantenir vincles d'amistat amb Rainer Maria Rilke, Stefan George i Auguste Rodin, entre altres. A casa seva, a Berlín, organitzava trobades i seminaris privats (el seu anomenat privatis simo), i n'escollia sempre personalment els participants.

1. GSG 1, 1999.

2. [N.T:. en alemany Habilitation, segona tesi que a Alemanya es requereix per poder accedir a una plaça de professor regular.]

3. [N.T.: Per més detall vegeu Köhnke, 1996.]

4. [N.T.: És a dir, com a professor sense salari fix de la universitat, segons el nombre d'estudiants i les seves contribucions. Per una idea més clara de la situació precària dels Privatdozenten de l'època (i d'avui dia encara), vegeu La ciència com a vocació, de Max Weber.] 


\section{Georg Simmel i les ciències socials}

Les contribucions de Simmel a les ciències socials són innombrables. Malauradament, però, la majoria romanen malenteses o han estat separades de les intencions i de la mà del seu creador original; d'aquesta manera, els seus orígens s'han oblidat. No obstant això, des de la teoria de sistemes fins a l'interaccionisme simbòlic, les diferents teories sociològiques que s'han elaborat posteriorment poden redescobrir en Simmel un dels seus pares fundadors.

L'interès de Simmel per les ciències socials, especialment per la sociologia, va despertar-se ben al principi de la seva carrera acadèmica. Després de participar als seminaris de Moritz Lazarus i Heymann Steinhtal (fundadors de la Völkerpsychologie -'psicologia dels pobles'), durant els seus anys d'estudiant, Simmel va esdevenir membre del cercle de Gustav Schmoller, on va familiaritzar-se amb els debats al voltant de l'economia política de l'època. En aquest marc va presentar la seva xerrada sobre «La psicologia del diner» 5 , que més endavant constituiria la primera pedra d'una de les seves obres cabdals, La filosofia del diner ${ }^{6}$. En els dos cercles (Schmoller i Lazarus-Steinthal) Simmel va esdevenir creixentment conscient i es va sensibilitzar respecte a les qüestions socials. El compromís de l'economista Schmoller amb aitals problemàtiques, l'èmfasi de Lazarus i Steinthal en el nivell «sobreindividual» (Überindividualität), juntament amb la cosmovisió relativista de Simmel i la seva insistència en la no validesa universal dels principis ètics, així com el seu interès en la teoria social de Herbert Spencer, van contribuir a formar la seva perspectiva sociològica. Aquestes diverses influències van amalgamar-se amb l'orientació filosòfica de l'autor, especialment amb el seu interès per Kant, formant una nova i àmplia perspectiva sociològica que, així i tot, encara havia de desenvolupar-se extensament al llarg de la seva vida.

La primera obra sociològica de Simmel, Sobre la diferenciació social (Über sociale Differenzierung) ${ }^{7}$, escrita ben a principis de la seva carrera acadèmica, va ser profundament influenciada per la filosofia de Herbert Spencer i les idees de Gustav Schmoller i el seu cercle. Lentament, de tota manera, a mesura que va anar passant la dècada de 1890, l'admiració que Simmel havia sentit per les teories d'Spencer va esdevenir creixent refús i es va distanciar més i més de tot enfocament evolucionista organicista de la sociologia. D'encà d'aquest refús, Simmel va incorporar els amplis coneixements que tenia de l'obra teòrica de Kant al seu pensament sociològic, i aquesta va esdevenir la base pels seus posteriors contactes i el diàleg establert amb els membres de l'escola noukantiana, amb els filòsofs Rickert $\mathrm{i}$ Windelband i amb el sociòleg que va romandre més proper a les seves idees: Max Weber. Aquest contacte amb el noukantianisme va influir en l'enfocament de Simmel envers les ciències socials a les acaballes del segle XIX i primers anys del XX.

5. GSG 2, 1989: 49-65.

6. GSG 6, 1989.

7. GSG 2, 1989. 
Gràcies a testimonis de l'època, sabem que Simmel fou un dels grans docents a la Universitat de Berlín i que els seus seminaris sempre eren plens a vessar d'estudiants ${ }^{8}$. És difícil, doncs, de comprendre per què Simmel no va tenir una carrera acadèmica més reeixida. Sabem, a través de la correspondència recuperada $\mathrm{i}$ dels intents de Gassen i Landmann de reconstruir l'obra i la vida de Simmel, que Georg Jellinek va esforçar-se, encara que sense obtenir resultats positius, per ajudar Simmel a aconseguir una càtedra ordinària a la Universitat de Heidelberg, l'any 1908. Seguidament, als anys 1912 i 1915, després de la mort de Jellinek, nous intents es van portar a terme per incorporar Simmel al professorat de Heidelberg; tots foren fallits. Ésser d'origen jueu, malgrat venia d'una família convertida al cristianisme i assimilada a la societat alemanya, va tenir de totes totes un rol decisiu en la manca de reconeixement que va rebre per part del sistema acadèmic. La seva peculiar i original concepció de les ciències socials, que divergia tant dels cànons establerts, així com el seu característic estil, tant parlat com escrit, $\mathrm{i}$ el seu ús continuat de l'assaig en lloc de recórrer a formes més «acadèmiques» i estandarditzades de prosa, varen contribuir també a la manca d'acceptació dins el marcadament formal i clàssic entorn universitari de l'Alemanya del moment. Sistemàticament, els intents d'aconseguir una càtedra per Georg Simmel varen ser aturats per la burocràcia de Baden. En una carta d'avaluació, escrita per l'historiador berlinès Schäfer, en relació amb la possible càtedra a Heidelberg l'any 1908, destaca l'argument principal del seu autor que nega l'aptitud del potencial candidat a esdevenir un bon catedràtic, atesos els seus orígens jueus i el fet que aquest «ésser jueu», seguint Schäfer, tenyia el caràcter de Simmel i els seus esforços intel-lectuals amb un fort relativisme i un deconstruccionisme que no podien ser bons per a cap estudiant ${ }^{9}$. Així, Simmel va haver de lluitar al llarg de la seva vida contra aquesta mena d'acusacions, mentre intentava a la vegada construir un «relativisme positiu» $\mathrm{i}$ constructiu, procurant mostrar que no tenia cap intenció de qüestionar "pilars absoluts», deixant-nos després amb les mans i les justificacions buides, sinó de mostrar que el sentit de l'«absolut» és també un producte d'accions i efectes recíprocs (Wechselwirkungen) i no pas quelcom "fonamentalment» absolut. D'aquesta manera, malgrat que Simmel, amb el pas del temps, va renegar de la seva obra de joventut Introducció a les ciències de la moral (Ein leitung in die Moralwissenschaften $)^{10}$, on el seu relativisme més crític $\mathrm{i}$ «negatiu» havia trobat el seu zenit, tot referint-s'hi com a «un pecat de joventut» ${ }^{11}$, les seves construccions teòriques anaven més enllà d'allò que la societat i el medi científic del seu temps podia assimilar, acceptar i perdonar.

Malgrat els canvis que la perspectiva sociològica de Simmel va experimentar al llarg dels anys, el seu interès per la disciplina va romandre viu fins

8. Gassen \& Landmann, 1958.

9. Gassen \& Landmann, 1958, Köhnke, 1996.

10. GSG 3, 1989 \& GSG 4, 1991.

11. Köhnke, 1996. 
al final. Així, quan Simmel en la seva carta a Célestin Bouglé del 2 de març de 1908 va escriure: «En aquests moments estic ocupat amb la publicació de la meva Sociologia, que finalment ha arribat al seu final»; i va afegir, frases més endavant, que el treball en aquest llibre "ha durat quinze anys», va indicar que el seu compromís amb la sociologia era tant un projecte a llarg termini com un camp d'interès ja arrelat en el pensament de l'autor. Considerant que la Sociologia no va ser publicada fins l'any 1908 i que, per tant, el treball en aquesta obra hauria d'haver començat cap a voltants de 1893 , en trobem la primera llavor en l'article «El problema de la sociologia», publicat l'any 1894. Simmel deuria pensar que aquest article era una contribució significant a la disciplina, atès que va intentar donar-lo a conèixer a l'estranger tant com li fou possible. Així, la traducció francesa d' «El problema de la sociologia» va aparèixer el setembre de 1894 , a la vegada que l'original alemany. La traducció americana va aparèixer als Annals de l'acadèmia americana de ciència política $i$ social $^{12}$ un any més tard $\mathrm{i}$, al tombant de segle, les traduccions italiana i russa ja estaven al mercat. La traducció americana és de particular significació, ja que, en una breu nota a peu de pàgina, Simmel va assenyalar que la sociologia és una ciència empírica, que requereix praxis, i que en cap cas no s'ha de considerar com una part independent de la filosofia, sinó com una ciència relacionada amb els problemes socials del moment (en el seu cas, de les darreries del segle dinou). La traducció italiana conté una versió modificada del text, en el qual Simmel va incloure clares referències a la seva polèmica teòrica amb Emile Durkheim.

A través d'una altra carta a Célestin Bouglé, aquesta vegada del 15 de febrer de 1894, sabem que després de la redacció d'«El problema de la sociologia» Simmel estava clarament engrescat amb aquesta nova disciplina i que no preveia en un futur immediat un canvi en la seva orientació envers cap altra àrea de recerca. Durant aquells anys es va moure i va treballar en la majoria d'àrees sociològiques per excel-lència, articulant els problemes socials considerats centrals del moment dins un marc sociològic, per exemple: els moviments obrer i feminista, la religió, família, prostitució, medicina i ètica, entre d'altres. Semblava que estava extraordinàriament interessat a posar les seves noves propostes i el seu marc teòric per a la constitució de la sociologia a la pràctica. També es va adonar que la institucionalització d'aquesta nova disciplina es veuria reforçada per la creació d'instituts i revistes especialitzades i, així, participà a l'Institut Internationale de Sociologie, del qual va esdevenir-ne el vicepresident, a l'American Journal of Sociology i també va col-laborar, tot i que només breument (a causa de diferències amb Emile Durkheim) a l'Année Sociologique $e^{13}$. Una altra via que Simmel va tenir en compte a l'hora d'intentar consolidar el rol de la sociologia en el món científic fou l'acadèmia, i també en aquesta àrea va demostrar el seu compromís, oferint i organitzant seminaris en el camp de la sociologia de forma ininterrompuda des de l'any 1893

13. Rammstedt, 1992: 4. 
fins a l'any de la seva marxa de Berlín, el 1914. El 15 de juny de 1898 va escriure a Georg Jellinek tot dient: «Estic absolutament convençut que el problema que he presentat [...] obre un nou i rellevant camp de coneixement, que l'ensenyament de les formes de sociació com a tals, abstretes dels seus continguts, realment representa una prometedora síntesi, una fructífera i immensa tasca i comprensió» ${ }^{14}$. Malgrat la seva intenció inicial, és ben clar que Simmel no va treballar contínuament en la Sociologia durant quinze anys: de l'any 1897 a l'any 1900 va treballar gairebé exclusivament en La filosofia del diner i també va trobar temps per a la publicació del seu llibre sobre Kant (1904); la segona impressió de la seva Introducció a la ciència moral (1904), que hagués volgut reescriure, ja que, passats els anys, no combregava amb moltes de les seves opinions de joventut (tasca que mai no va aconseguir portar a terme); la nova versió i edició dels Problemes de la filosofia de la història (1905), La filo sofia de la moda (1905) i La religió (1906/1912) també van ser elaborades durant aquest període ${ }^{15}$. A «El problema de la sociologia» va qüestionar per primera vegada la manca d'un ben definit objecte d'estudi per a l'emergent disciplina i va proposar-se desenvolupar una perspectiva sociològica específica, que permetés definir un objecte d'estudi distint, per tal, en bona part, d'assolir legitimitat $i$, a la vegada, un format cientificoacadèmic per a una disciplina que estava essent atacada des de diferents, i més ben assentades, línies de foc. Conscient que aquesta crida no havia estat escoltada, Simmel va carregar sobre les seves espatlles el projecte d'escriure un treball més ampli, on s'exemplifiquessin i es posessin en pràctica les principals línies que havia presentat com a centrals per l'emergent disciplina. D’aquesta manera, a les gairebé mil pàgines de la Sociologia, va ajuntar miques i trossos, provinents d'assaigs i texts que havia anat escrivint al llarg dels anys transcorreguts entre 1894, any de la publicació d' «El problema de la sociologia», i 1908. Simmel, com prova el testimoni que ens han deixat les seves cartes, era conscient del caràcter incomplet d'aquesta obra, però va intentar salvar-la, tot afirmant que només havia estat un primer intent de posar en pràctica allò que havia suggerit quinze anys abans i que no havia estat pres en suficient consideració per la comunitat científica. Simmel no desitjava, en aquells moments, figurar com a sociòleg. Diverses raons ho expliquen: en aquell temps, la sociologia no era una disciplina establerta al món acadèmic $i$, per tant, no li podia permetre obtenir una càtedra en aquest camp (i oferia poc reconeixement) ${ }^{16}$. De tota manera, no la va abandonar mai de forma completa, i va seguir escrivint sobre temes de religió, cultura femenina i família. Podríem dir que, senzillament, va ampliar la seva perspectiva per incloure-hi la filosofia de la vida (Lebensphilo sophie) i estudis culturals en general. Simultàniament, va contribuir a la fun-

\section{Rammstedt, 1992: 5.}

15. Rammstedt, 1992.

16. [N.T.: Cal recordar que, com s'ha destacat fa algunes pàgines, Simmel no va aconseguir una plaça amb salari a la universitat — una càtedra de filosofia — fins quatre anys abans de la seva mort, l'any 1914.] 
dació de l'associació alemanya de sociologia (Deutsche Gesellschaft für Soziologie), on hi va ocupar un alt càrrec fins l'any 1913.

La Sociologia, tot i abraçar un llarg període de la producció de Simmel, també marca el final de l'època durant la qual va estar més influenciat per Kant i, alhora, representa un gir del seu interès teòric; atès que, d'ençà de la seva publicació, va refusar l'etiqueta de «sociòleg» i va intentar retornar a la filosofia. Així, després que la gran Sociologia ${ }^{17}$ veiés la llum, no va tornar a publicar cap text sociològic fins passats nou anys (tot i que, com ja s'ha mencionat, va seguir oferint seminaris en sociologia fins l'any 1914) i va dirigir els seus esforços envers els camps de la filosofia, la història i la filosofia de l'art. En la producció teòrica de Simmel d'aquests anys hi figuren, entre altres obres, Kant $i$ Goethe (1906/1916), Goethe (1913), Kant (1904/1913/1918), Principals problemes de la filosofia (Hauptprobleme der Philosophie, 1911), Cultura filosòfica (1911/1918) i Rembrandt (1916). Aquesta nova orientació va ser acompanyada i, en part, motivada pel coneixement i reconeixement per part de Simmel de l'obra de Henri Bergson i per la seva inclinació cap a la Lebensphilosophie ('filosofia de la vida') ${ }^{18}$. D'aquesta manera, la «vida» va esdevenir el focus principal de la seva obra teòrica $i$, consegüentment, va relegar el concepte de «societat» a un rol secundari. Durant aquests anys, Simmel va dedicar-se a estudiar artistes, la seva producció i com, a través de la seva imminent originalitat, la relació entre la «vida» i la seva expressió formal s'havia anat cristal.litzant en les seves obres. Semblava que Simmel havia perdut l'interès per la sociologia; des de feia anys no hi havia dedicat una sola línia. De cop i volta, però, l’any 1917, un any abans de la seva mort, va escriure les Qüestions fonamentals de la sociologia (Grund fragen der Soziologie), la "petita sociologia", com se la sol anomenar en contrast amb la Sociologia de 1908. L'impuls per escriure aquest llibre va venir d'una editorial ${ }^{19}$, que tenia la intenció de publicar una introducció a la sociologia i que, gràcies a l'èxit de vendes d'altres llibres de Simmel (publicats en part per la mateixa editorial), va optar per fer-li l'encàrrec. Ara, però, si Simmel hagués deixat de banda la seva reflexió sociològica, només li hauria estat necessari retornar als seus vells llibres i reescriure'n trossos en una forma més curta. No va ser pas així, i a les Qüestions fonamentals de la sociologia, cent pàgines escasses, va presentar la conclusió de les seves reflexions sociològiques, en les quals va amalgamar els seus anteriors estudis de les formes de sociació amb una perspectiva de la filosofia de la vida. Aquesta és una perspectiva sociològica que va caure en l'oblit després de la mort de l'autor i que encara espera ésser revitalitzada; es tracta d'una original

17. [N.T.: «La gran sociologia» (grosse Soziologie) és el sobrenom amb el qual es distingeix la sociologia de 1908 de la "petita sociologia" (o kleine Soziologie), que correspon a les Qües tions principals de sociologia (Grundfragen der Soziologie) de 1917.]

18. Sobre aquest tema, vegeu Fitzi, 1998, 1999.

19. «Sammlung Göschen», G.J. Göschen'schen Verlagshandlung G.m.b.H., Berlín \& Leipzig. 
perspectiva que conté un ampli ventall de possibilitats per a les noves generacions de sociòlegs ${ }^{20}$.

\section{L'objecte de la sociologia}

En un temps en el qual la sociologia estava encara lluny d'esdevenir una disciplina establerta i tot just començava a fer els seus primers passos, Simmel va intentar alliberar-la de la pesada càrrega d'haver d'ésser la «ciència de la societat». Segons l'autor, aquesta càrrega era impossible de portar a les espatlles, sobretot per una diciplina recentment nascuda com la sociologia, ja que ésser la ciència de la societat implicava haver de lluitar contra disciplines ja assentades i establertes per la legitimitat del propi objecte d'estudi. El dret, la història, la psicologia i l'etnologia, totes podien argumentar que tenien la societat com a objecte, deixant així la sociologia amb la simple pretensió d'incloure-les totes. Des d'aquesta perspectiva, la «societat» fóra un objecte que ho englobaria tot, però, al mateix temps, escaparia de la investigació científica com sorra entre els dits. Simmel, igual que Max Weber dues dècades més endavant, va contribuir a la desmitificació de "la societat» com a entitat essencial (com apareix a la sociologia del segle XIX i encara hi roman, fins a cert punt, a les sociologies de Tönnies i Durkheim) i va copsar-la com un procés dinàmic, com un esdevenir continuat, que no és més que la suma de les formes de sociació existents ${ }^{21}$.

Els individus, així com la societat o les societats, no són unitats en ni per si mateixos, tot i que ens poden semblar unitats autosuficients segons la distància que, com a observadors, interposem entre nosaltres i els objectes observats. En qualsevol cas, tal com Simmel va argumentar en les seves Qüestions fona mentals de la sociologia ${ }^{22}$, si únicament prenem els individus i pretenem, adoptant distància, comprendre la «societat», o un fenomen social, no arribarem mai al nostre fi. Seguint aquest autor, quan formulem una pregunta sociològica, hem de partir de les formes de sociació, que es construeixen en accions i efectes recíprocs (Wechselwirkung). Aquest concepte fou emprat per Simmel al llarg de la seva obra, ja sigui com a sinònim d'interaccions, o bé, seguint la definició kantiana, per caracteritzar les mútues relacions que entrellacen tots els elements que coincideixen en un mateix punt de temps i espai ${ }^{23}$. La diferència entre els dos possibles significats del concepte, o, més precisament, la dife-

20. La darrera obra de Simmel va ésser una contribució filosòfica a la Lebensphilosophie amb el títol de Lebensanschauung [una possibilitat de traducció seria Visió de vida, però no m'atreviria pas a dir-ne l'última paraula, NCM] (1918, GSG 16).

21. Ésser la suma de les formes de sociació existents no és sinònim d'ésser la suma dels individus que formen la societat. Per més detall, vegeu el primer capítol de Les qüestions fona mentals de la sociologia, GSG 16.

22. GSG 16: 62-68.

23. Simmel, Georg, The Philosophy of Money, traduït i editat per David Frisby i Tom Bottomore, Routledge, Londres, 1978. 
renciació entre els dos conceptes amagats rere la mateixa paraula, ha estat corregida en la traducció anglesa de La filosofia del diner. Fins aleshores, els traductors de l'obra de Simmel havien caigut en el freqüent error de traduir, sense més, Wechselwirkung per 'interacció'. Seguint Simmel, allò que té lloc entre els individus constitueix l'objecte de la sociologia; ni els individus en si mateixos, ni la societat com a tot. La societat no és més que la suma de les formes de sociació ${ }^{24}$, un procés continuat en el qual, i a través del qual, aquestes formes s'entrelliguen i es combinen per formar un $\operatorname{tot}^{25}$.

\section{El concepte de «forma»}

Prenent el concepte d'accions i efectes recíprocs com a punt de partida, arribem a una perspectiva que, de fet, és comuna a totes les ciències humanes i socials: la sociologia com a mètode. Per tal de construir la sociologia com una disciplina independent, amb un objecte d'estudi específic, cal, segons Simmel, dibuixar una línia analítica entre formes i continguts, essent les formes els canals, les maneres i els tipus d'interacció entre els individus, grups socials $\mathrm{o}$ institucions, i els contiguts allò que ens condueix a actuar, les emocions o les metes dels éssers humans. D’aquesta manera, les formes de sociació són concebudes com l'objecte d'anàlisi d'una sociolgia científica, i això, seguint ben de prop Simmel, només pot ser possible d'una manera empírica. Els continguts, per altra banda, constituiran l'objecte d'anàlisi d'altres disciplines, com la psicologia o la història.

Simmel considerà la sociologia orientada envers les formes de sociació com la sociologia pura, genuïna, tal com podem observar quan llegim el subtítol de Sociologia ${ }^{26}$. Per tal que els individus puguin esdevenir socials, necessiten poden comptar amb formes per tal de canalitzar («formar») els seus continguts, i a través d'elles la participació i interpretació d'interaccions socials esdevé possible. Les formes són independents dels continguts i, a l'hora d'analitzar-les, han d'ésser abstretes dels continguts i dels individus particulars amb els quals apareixen indissolublement lligades: la qüestió de les formes socials no inclou la qüestió de les relacions específiques entre participants específics involucrats en interaccions concretes; la nostra atenció s'ha de centrar en tot allò que succeeix entre ells. Així, per a l'anàlisi de les formes socials, els individus concrets que hi estiguin involucrats són irrellevants. Els éssers humans, amb els seus continguts particulars, només esdevenen socials quan intenten realitzar, portar a terme, aitals continguts, $i$, aleshores, s'adonen que això només és possible dins un marc social: per tal d'expressar-se, exterioritzar-se en un medi social, necessiten formes de sociació. Formes són, doncs,

24. [N.T.: És a dir, la suma de tot allò que esdevé entre els individus i que es va cristal.litzant en formes concretes.]

25. GSG 11: 19.

26. [N.T.: O llegint el tercer capítol de Qüestions fonamentals de la sociologia, dedicat a la sociologia pura o formal i basat en l'exemple de la sociabilitat (Geselligkeit).] 
objectivacions socials que s'imposen, amb les seves normes, sobre individus concrets; una imposició que només pot ser anul.lada a través de l'aïllament. Aquestes imposicions i coaccions són part de la sociació i tenen un important paper en la teoria de Simmel, el qual va mantenir que, de fet, no som socials per naturalesa. Simmel va col-locar la sociació, com a producte d'accions i efectes recíprocs, al centre de la seva sociologia pura (reine) o formal. Exemples paradigmàtics de formes de sociació serien, segons Simmel, el secret, la competitivitat o la subordinació.

Així, el dualisme entre forma i contingut, a partir del qual trobem múltiples formes per canalitzar un mateix contingut, va esdevenir creixentment rellevant en la sociologia de Simmel. Ara, però, amb la introducció de la perspectiva de la filosofia de la vida a la seva obra, el concepte de forma va deixar d'ésser contrastat amb el concepte de contingut i va formar una nova binaritat amb el concepte de vida. En aquest període tardà de l'obra i la vida de l'autor, les formes són concebudes com a cristal.litzacions de l'incontenible fluir de la vida. Les formes són maneres d'expressar la vida, atès que la vida no pot expressar-se per si mateixa. Simmel va explicar aquesta aparent paradoxa afirmant que la vida és més-vida i més-que-vida (Mehr-Leben i Mehrals-Leben). El concepte més-vida implica senzillament que aquest continu fluir connecta cada moment, en si mateix complet, amb el següent; més-quevida implica que la vida no és vida si no transcendeix els seus propis límits i esdevé cristal.litzada en una forma. La vida esdevé art, o ciència, per exemple; la vida esdevé cristal.litzada i així s'expressa i es completa. Per exemple, seguint aquesta perspectiva, hauríem d'entendre l'art com una forma d'expressar (exterioritzar, äussern) la vida a través de formes (artístiques, estètiques). Esbrinar com aquesta perspectiva pot aplicar-se a la sociologia pot ser una tasca difícil d'aconseguir; el primer pas cap a la claretat el va fer el mateix Simmel en la seva obra Qüestions fonamentals de la sociologia.

\section{Tu i jo}

Distanciant-se deliberadament del concepte d'alter ego, Simmel va destacar la importància que el concepte del $t u$ hauria de tenir en tota teoria sociològica. Així, va articular i situar aquest concepte dins la seva teoria del coneixement. Paral-lelament al qüestionament kantià de la natura, Simmel va preguntar-se: "Com és possible la societat?», en la seva primera i tan coneguda digressió de la gran Sociologia. Per tal de contestar aquesta qüestió va proposar tres apriorismes. El primer assenyala que el «tu» $\mathrm{i}$ el «jo» es veuen entre ells «fins a cert punt generalitzats» ${ }^{27} \mathrm{i}$, per tant, cal assumir que la percepció que cada individu té de l'altre (del "tu») és una percepció, en un grau més o menys elevat, tipificada, generalitzada. El segon apriorisme manté que cada individu, en tant que «element d'un grup, no és només part de la societat, 
sinó que, a part d'això, és quelcom més», i el seu ésser únic, la seva individualitat, deriva de la dualitat d'estar i no estar socialitzat a la vegada ${ }^{28}$. El tercer apriorisme fa referència a la posició assignada dins la societat a cada individu: "que cada individu està, a partir de les seves qualitats, destinat a una posició particular dins el seu àmbit social: que aquesta posició, que existeix com feta per a ell, realment existeix en el conjunt social - aquesta és la suposició segons la qual tot individu viu la seva vida social» ${ }^{29}$; això és el que Simmel tenia en ment quan va escriure sobre «el valor general de la individualitat».

Aquests apriorismes sociològics, orientats envers el rol, el tipus i les relacions entre l'individu i la societat, també ens permeten entendre els aspectes centrals de la metodologia de Simmel, que pot ser emmarcada dins els conceptes de «diferenciació», en el sentit de divisió i diferència, $\mathrm{i}$ «dualisme», en el sentit d'una oposició irreconciliable i tràgica dels elements del tot social.

\section{Una proposta per a tres sociologies}

Com a ciència independent, la sociologia havia de romandre, seguint Simmel, en relació propera amb les "principals àrees problemàtiques» de la vida social $^{30}$, fins $\mathrm{i}$ tot quan aquestes àrees estan distanciades les unes de les altres. Ja l'any 1895 va afirmar que el nom que calia donar a aital grup no era pas d'importància, atès que la qüestió real era identificar problemes i solucionarlos, i no pas discutir els noms que s'haurien de donar a grups particulars ${ }^{31}$. Simmel tornà a emfasitzar l'orientació de la sociologia envers àrees de problemes l'any 1917, en la redacció de les Qüestions fonamentals de la sociolo gia. Així, en un intent d'aproximar aitals qüestions fonamentals (és a dir, les relacions existents entre la societat i els seus elements, els individus) es va concentrar en tres grups diferents de problemes amb exemples concrets, particularment a la tercera part del primer capítol. La primera àrea de problemes s'orienta envers l'objectivitat com a component de l'esfera social de l'experiència; la segona àrea inclou els fets de la vida, en els quals i a través dels quals els grups socials són realitzats; i la tercera àrea emfasitza la significació del «fet

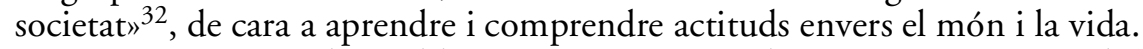
Aquestes tres àrees de problemes corresponen a les seves tres proposades sociologies: primerament, la «sociologia general», que, onsevulla que hi hagi societat, pren per objecte les relacions centrals entre els individus i les construccions socials resultants; l'objectiu d'aquesta sociologia general és mostrar quins valors orientats i creats recíprocament conformen aitals construccions socials i els imaginaris dels propis individus. Simmel va exemplificar aquest

31. Annals of the American Academy of Political and Social Science, 6, 1895, p. 420.

32. GSG 16, 1999: 84. 
tipus d'anàlisi en el segon capítol de la "petita sociologia», prenent les relacions que existeixen entre "el nivell social i el nivell individual», una perspectiva que, a la vegada, sociologitza la teoria de masses. Segonament, la sociologia "pura o formal» es concentra en les múltiples formes que els individus empren per canalitzar les seves motivacions i metes, impulsos i emocions (en termes simmelians, els seus continguts) en accions i efectes recíprocs. Seguint Simmel, cada "forma» guanya, entrelligada en aquests processos socials, una vida pròpia, que està desarrelada dels continguts ${ }^{33}$. Aquí troba el seu sòl la teoria simmeliana de la sociabilitat (Geselligkeit), que Simmel presenta com a exemple clau en el seu tercer capítol de les Qüestions fonamen tals. La tercera àrea de problemes, que Simmel identificà com la sociologia filosòfica, marca els límits entre la sociologia empírica, exacta i orientada envers la comprensió immediata d'allò factual ${ }^{34} \mathrm{i}$ els intents de complementar l'empíria a través d'hipòtesis i especulació, d'inevitable caràcter fragmentari, per tal d'acostar-se a una visió global. En el quart capítol de les Qües tions fonamentals, titulat «L'individu i la societat en les visions de la vida dels segles XVIII i XIX», Simmel va il.lustrar la necessitat abstracta que hi ha d'assolir llibertat individual, que hauria d'ésser entesa com una reacció a les creixents obligacions i coercions socials contemporànies. D’aquesta manera, Simmel feia referència als conflictes generals entre individu i societat, que deriven de l'irreconciliable conflicte entre la idea de societat com un tot, que «requereix dels seus elements la unilateralitat de funció parcial» i l'individu, que se sap a si mateix només parcialment socialitzat i per si mateix vol esdevenir un tot $^{35}$.

\section{Simmel i la sociologia moderna}

La significació teòrica de Simmel per la sociologia contemporània rau en les múltiples possibilitats teòriques, que poden ésser derivades de la seves «sociologies». Exemples de la seva influència són facils de trobar en l'interaccionisme simbòlic, en la teoria del conflicte, en el funcionalisme, en la psicologia social $i$ en les diverses teories de la modernitat. Simmel també va introduir dins la disciplina sociològica la utilització de l'assaig com a forma acadèmica d'anàlisi, i les seves digressions dins la gran Sociologia són de menció obligada, atès que totes han estat arreu reconegudes com a clàssics; recordeu, per exemple, les seves digressions sobre "La carta», "La fidelitat i l'agraïment» (Treue und Dankbarkeit) o "L'estrany» (Der Fremde ${ }^{36}$ ). Però, sobretot, la sociologia li deu a Simmel el fet d'haver-la alliberat de la fixació en el dualisme «individu-societat» com a objecte òntic —un camí sense retorn.

36. [Altres traduccions possibles foren «El foraster» $\mathrm{o}$ «L'estranger», personalment opto per «L'estrany», ja que em sembla que és la traducció més exacta del mot alemany Fremder, NCM]. 


\section{Bibliografia}

Dahme, Heinz-Jürgen; Rammstedt, Otthein (ed.) (1995). Georg Simmel. Schriften zur Soziologie. Eine Auswahl. Frankfurt am Main: Suhrkamp.

Gassen, Kurt; Landmann, Michael (1993). Buch des Dankes an Georg Simmel. Brie fe, Erinnerungen, Bibliographie. Zu seinem 100. Geburtstag am 1. März 1958. Berlín: Duncker \& Humblot.

GSG, Georg Simmel Gesamtausgabe, editat per Otthein Rammstedt, Frankfurt a.M.: Suhrkamp.

GSG 1 (1999). Das Wesen der Materie (1881). Abhandllungen 1882-1884. Rezensionen 1883-1901, editat per Köhnke, Klaus Christian.

GSG 2 (1989. Aufsätze 1887-1890. Über sociale Differenzierung (1890). Die Proble me der Geschichtsphilosophie (1892), editat per Dahme, Heinz-Jürgen.

GSG 3 (1989). Einleitung in die Moralwissenschaft. Eine Kritik der ethischen Grund begriffe. Erster Band (1892/1904), editat per Köhnke, Klaus Christian.

GSG 4 (1991). Einleitung in die Moralwissenschaft. Eine Kritik der ethischen Grund begriffe. Zweiter Band (1893), editat per Köhnke, Klaus Christian.

GSG 5 (1992). Aufsätze und Abhandlungen 1894-1900, editat per Dahme, HeinzJürgen \& Frisby, David, 1992.

GSG 6 (1989). Philosophie des Geldes (1900/ 1907), editat per Frisby, David \& Köhnke, Klaus Christian.

GSG 7 (1995). Aufsätze und Abhandlungen 1901-1908, Band I, editat per Kramme, Rüdiger, Rammstedt, Angela \& Rammstedt, Otthein.

GSG 8 (1993). Aufsätze und Abhandlungen 1901-1908, Band II, editat per Cavalli, Alessandro \& Krech, Volkhard.

GSG 9 (1997). Kant (1904/1913/1918). Die Probleme der Geschichtsphilosophie, 2 Fas sung (1905/1907), editat per Oakes Guy \& Röttgers.

GSG 10 (1995). Philosophie der Mode (1905). Die Religion (1906/1912). Kant und Goethe (1906/1916). Schopenhauer und Nietzsche (1907), editat per Behr, Michael, Krech, Volkhard \& Schmidt, Gert.

GSG 11 (1992). Soziologie. Untersuchungen über die Formen der Vergesellschaftung (1908), editat per Rammstedt, Otthein.

GSG 14 (1996). Hauptprobleme der Philosophie (1910/1927). Philosophische Kultur (1911/1918), editat per Kramme, Rüdiger \& Rammstedt, Otthein.

GSG 16 (1999). Der Krieg und die geistigen Entscheidungen (1917). Grundfragen der Soziologie (1917). Vom Wesen des historischen Verstehens (1918). Der Konflikt der modernen Kultur (1918). Lebensanschauung (1918), editat per Fitzi, Gregor \& Rammstedt, Otthein.

KÖHNKE, Klaus Christian (1996). Der junge Simmel in Theoriebeziehungen und sozia len Bewegungen, Frankfurt am Main: Suhrkamp.

Rammstedt, Otthein, «Programm und Voraussetzungen der Soziologie Simmels», a Simmel-Newsletter 2, 1992, p. 3-21.

Simmel, Georg (1978). The Philosophy of Money, traduït i editat per D. Frisby \& T. Bottomore, Londres: Routledge. 